\title{
Mecanismo de inserción del Laboratorio Tecnológico del Uruguay en el Parque Tecnológico Industrial del Cerro
}

\author{
Márquez, L. ${ }^{(1)}$, De Giuda, M. ${ }^{(1)}$ \\ Contacto: Imarquez@latu.org.uy \\ (1) Gerencia de Gestión Empresarial - Laboratorio Tecnológico del Uruguay (LATU)
}

\begin{abstract}
Resumen
EI Laboratorio Tecnológico del Uruguay, LATU, teniendo en cuenta su misión: "Impulsar el desarrollo sustentable del país y su inserción internacional a través de la innovación y transferencia de soluciones de valor, en servicios analíticos, metrológicos, tecnológicos, de gestión y evaluación de la conformidad de a cuerdo a la normativa aplicable", está trabajando en el apoyo a las micro, pequeñas y medianas empresas del país.

Como estrategia para contribuir al logro de la misión, se ha iniciado una política de descentralización, eligiendo zonas de actividad con requerimientos similares, en cuanto a las necesidades de mejora de la competitividad de las empresas.

En la zona de Montevideo llamada el Cerro, el gobierno municipal gestiona un Parque Tecnológico Industrial, PTIC, apoyando y alojando en su predio, 58 empresas. Este Parque se puede ver como un conglomerado de empresas, en una misma zona, con necesidades similares.

El mecanismo de inserción del LATU en el PTIC, ha contado con una herramienta fundamental que es la instalación de una oficina en el propio Parque, cuyo objetivo principal es facilitar y asegurar la contribución del LATU al desarrollo y competitividad de las mipymes allí agrupadas.
\end{abstract}

\begin{abstract}
Attending to the Technological Laboratory of Uruguay (LATU)'s mission, to promote the sustainable development of the country and its international insertion through innovation and transfer of valuable solutions, it is working on support for micro, small and medium companies. As a management strategy to achieve the mission, a policy of decentralization, approaching to the enterprises, it's being implemented.

In this context, it has been developed a methodology for insertion in the Industrial Technological Park of Cerro, PTIC. This park, which is managed by the municipal government, agglomerates a group of companies, in the same area with similar needs.

The LATU's mechanism of insertion in the PTIC, has counted on with a principal tool, which was the establishment of an office within the park. The daily and direct contact with companies has fluidized the dialogue of the businessmen with technicians and professionals, as well as with institutions that offer support programs, so projects of training and strengthening have been generated.

The most important result has been made available to companies, tools to develop and improve their competitiveness in a genuine and durable way, since companies and people were strengthened.
\end{abstract}

\section{Descripción general del PTIC}

Como forma de ordenar el territorio del predio y con la intención de contribuir a una mejor infraestructura para las empresas, el parque está dividido en cuatro áreas físicas bien delimitadas: Área Medioambiental, Área Alimenticia, Edificio Azul (Producción) y Edificio Verde (Innovación Tecnológica). En la figura 1 se muestra una vista parcial del PTIC.

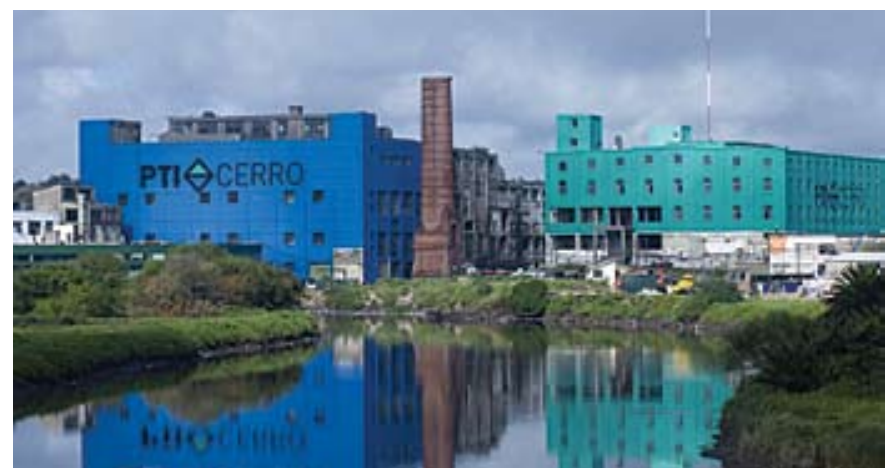

Figura 1 - Vista parcial del Parque Tecnológico Industrial del Cerro, PTIC - Montevideo.

Las empresas que componen el PTIC, son de todos los rubros, a diferencia de otros parques que se caracterizan por agrupar empresas de un mismo rubro. Esto agrega dificultades adicionales para compatibilizar requisitos de higiene, infraestructura, seguridad y accesibilidad. Por otro lado esta característica puede enriquecer al Parque y aparecen posibilidades interesantes a la hora de articular las distintas actividades.

El Parque está formado por micro y pequeñas empresas en su mayoría. En la figura 2 se muestra la distribución de las empresas por rubro de actividad.

7 empresas en el área de alimentos

9 en Gestión de Residuos y Reciclaje

3 en el área textil

9 en servicios industriales (metalúgia, reparación de equipos, instalaciones, electromecánica, ascensores, transformadores, etc)

2 en servicios informáticos

4 en servicios (enfermería, portería, serenos)

2 carpinterías

1 materias primas para cosméticos

1 esterilización

14 en fabricación de distintos productos (artículos plásticos, adhesivos, grifería, artículos de vidrio, calzado, pigmentos, artículos metálicos, artículos eléctricos, bolsas de papel, pallets, juguetes, etc.)

Figura 2 - Distribución de rubros de las empresas del PTIC 


\section{Etapa 1 - CONTACTO INICIAL}

$\begin{array}{ll}\text { Etapa } 2 \text { - ACERCAMIENTO } & * \text { Oficina } \\ & * \text { Diagnóstico }\end{array}$

Etapa 3 - PROFUNDIZACIÓN * Proyectos

Figura 3 - Etapas de la Metodología

El PTIC se encuentra en continuo crecimiento ya que se van incorporando nuevas empresas al predio.

\section{Metodología de inserción}

Como forma de acercar las capacidades del LATU a las empresas del PTIC, y así propiciar que mejoren su competitividad, se trabajó en varios ámbitos, en distintas etapas y con distintos actores. La metodología para concretar el apoyo, se puede presentar en las tres etapas que se muestran en la figura 3.

A continuación se describe cada una de las etapas mencionadas.

\section{Etapa de contacto inicial}

En esta etapa de vinculación se conocieron los diferentes mecanismos internos del PTI, así como sus estructuras formales, de esta forma se diseñaron y evaluaron diferentes mecanismos de inserción. En esta etapa se visualizó la necesidad de una presencia permanente que sirviera de catalizador para propiciar la gestión de conocimiento en el PTI, no solamente referido al conocimiento de los servicios y oportunidades de la estructura, sino también con el exterior, de programas, proyectos y otros dadores de conocimientos.

Las actividades realizadas en esta etapa fueron:

- Visitas al Parque y reuniones con la CAPIT, Comisión Administradora del Parque. Con estas se logra determinar la forma de trabajo.

- Talleres con las empresas. Esta metodología de trabajo permitió detectar en forma general, necesidades, expectativas y solicitudes de las empresas y de la Comisión.

- Visita de Técnicos de algunas áreas del LATU, como Proyectos Alimentarios y Medio Ambiente, así se determinan las diferentes posibilidades de trabajo en sus áreas.

\section{Etapa de acercamiento}

El objetivo de esta etapa fue el establecer mecanismos de comunicación, situando al LATU como un protagonista de la realidad del PTI, y como agente de profundización del emprendedurismo y su profesionalización.

Las actividades llevadas a cabo durante esta etapa fueron:

- Instalación de una oficina en el edificio del Parque. Con el objetivo de facilitar el contacto y los aportes al desarrollo y competitividad de las empresas.

- Diagnóstico de las empresas. Mediante una visita a cada empresa, evaluar sus necesidades y conocer sus solicitudes.

Para realizar el Diagnóstico se elaboró un cuestionario para detectar las necesidades de las empresas. El cuestionario abarcó los siguientes temas: Informaciones generales; Personal de la empresa; Productos (Especificaciones, venta, promoción, innovación); Equipamientos; Producción y clientes; Materias Primas y Servicios; Salud Ocupacional y Seguridad; Información Ambiental (Residuos, Efluentes, Emisiones); Organización de la empresa; Necesidades; Empresa en relación al PTI.

Como método para la recopilación de datos, se realizó una visita a cada empresa, en la que se presentó la oficina y el objetivo del programa de apoyo al PTIC. Durante la visita la empresa tuvo oportunidad de expresar sus inquietudes, necesidades, dificultades y proyectos que apunten a mejorar su competitividad. Se completó, en esta oportunidad, el cuestionario elaborado. De las 58 empresas que forman parte del Parque Tecnológico Industrial del Cerro,
35 fueron contactadas, se visitaron y diagnosticaron 26. De las restantes, una parte importante, está en proceso de instalación o no estaban disponibles para trabajar en el momento del diagnóstico. Las principales conclusiones a las que se llegó luego del análisis de la información brindada por las empresas, se resumen en la figura 4.

\section{Resultados del Diagnóstico:}

Tamaño: La mayoría de las empresas del Parque son micro o pequeños emprendimientos. Algunas de las empresas son nuevas y las que ya tienen una trayectoria, en general, desarrollan en el parque, proyectos nuevos.

Gestión: En cuanto a la gestión de las empresas, una empresa está certificada ISO 14001, una tiene la certificación ISO 9001, una está en proceso de implantación del Sistema de Gestión de la Calidad y dos en proceso de implantación de Buenas Prácticas (GMP).

Innovación: Se caracterizan además por concretar ideas innovadoras, por desarrollar nuevos productos o productos que no se fabricaban en el país. 9 empresas están actualmente trabajando en proyectos de innovación, de las cuales 4 están desarrollando proyectos PDT (apoyo del Ministerio de Educación y Cultura).

Necesidades: Otra de las características de estas empresas, es que con pocos elementos, poca inversión y mucho esfuerzo, han logrado poner en funcionamiento un proceso productivo. Al no poseer suficiente capital, tienen dificultades económicas para el funcionamiento de la empresa y no pueden invertir en asistencia técnica, consultoría o incorporación de personal calificado a la empresa. Muchas de las empresas manifestaron carencias en la gestión y/o gerencia de su pyme, además de la falta de recursos humanos capacitados para las diferentes áreas de la empresa. Para fortalecer la dirección, necesitan recibir capacitación en gestión, administración, plan de negocios, etc. La mayoría de las empresas manifestaron interés en el tema Calidad, tanto en la capacitación, como en comenzar un sistema de gestión e incluso llegar a la certificación.

La mayoría de las empresas necesitan apoyo en buenas prácticas, mejorar procesos, procedimientos de trabajo, mejorar control de calidad, etc.

\section{Figura 4 - Diagnóstico de las empresas del PTIC}

\section{Etapa de Trabajo Conjunto - Profundización}

El objetivo de esta etapa es la de trabajar junto con las diferentes empresas de PTI, para la mejora continua de los procesos, productos y gestión de cada una. El cumplimiento de este objetivo, permite la sobrevivencia de las empresas, pero se busca adicionalmente el crecimiento sostenido. La transformación en la mentalidad de una empresa serrucho, que solo innova a requisitos o ideas geniales y después no incorpora el conocimiento y lo sistematiza, a empresas escalera, que continúan su mejora en forma sistemática de tal manera que continuamente se detectan pequeñas mejoras, se sistematizan, se aprenden y se continúa. En la figura 5 se presenta un esquema para visualizar esta diferencia.

Dentro de las actividades que se fomentaron durante esta etapa, se 


\section{Emprevanougaton}

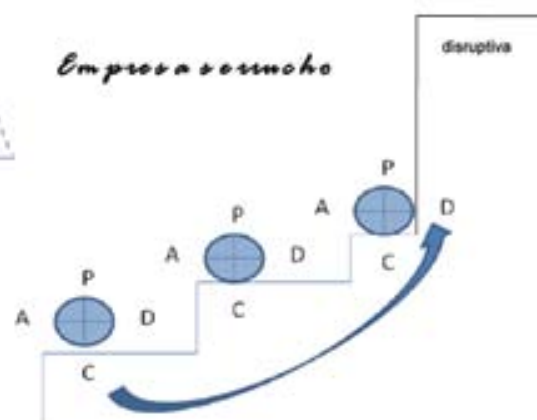

Figura 5 - Diferencia entre la empresa serrucho y la empresa escalera.

destacan las siguientes:

- Asistencia personalizada a las empresas, mediante proyectos para asistencia técnica, desarrollo de productos, capacitación del personal en Buenas Prácticas de manufactura, evaluación del desempeño de prototipos, adecuación para el cumplimiento de normativa, implantación de Sistemas de Gestión de la Calidad, Ambiental y de Seguridad y Salud Ocupacional.

- Talleres y Capacitación colectiva, abiertos a todas las empresas.

- Ayuda en la formulación de proyectos, para presentar ante organismos con programas de apoyo a Pymes.

En la figura 6 se presentan imágenes del proyecto de apoyo a una empresa del sector Alimenticio del Parque.

En la figura 7 se presentan imágenes algunos de los Talleres brinda-
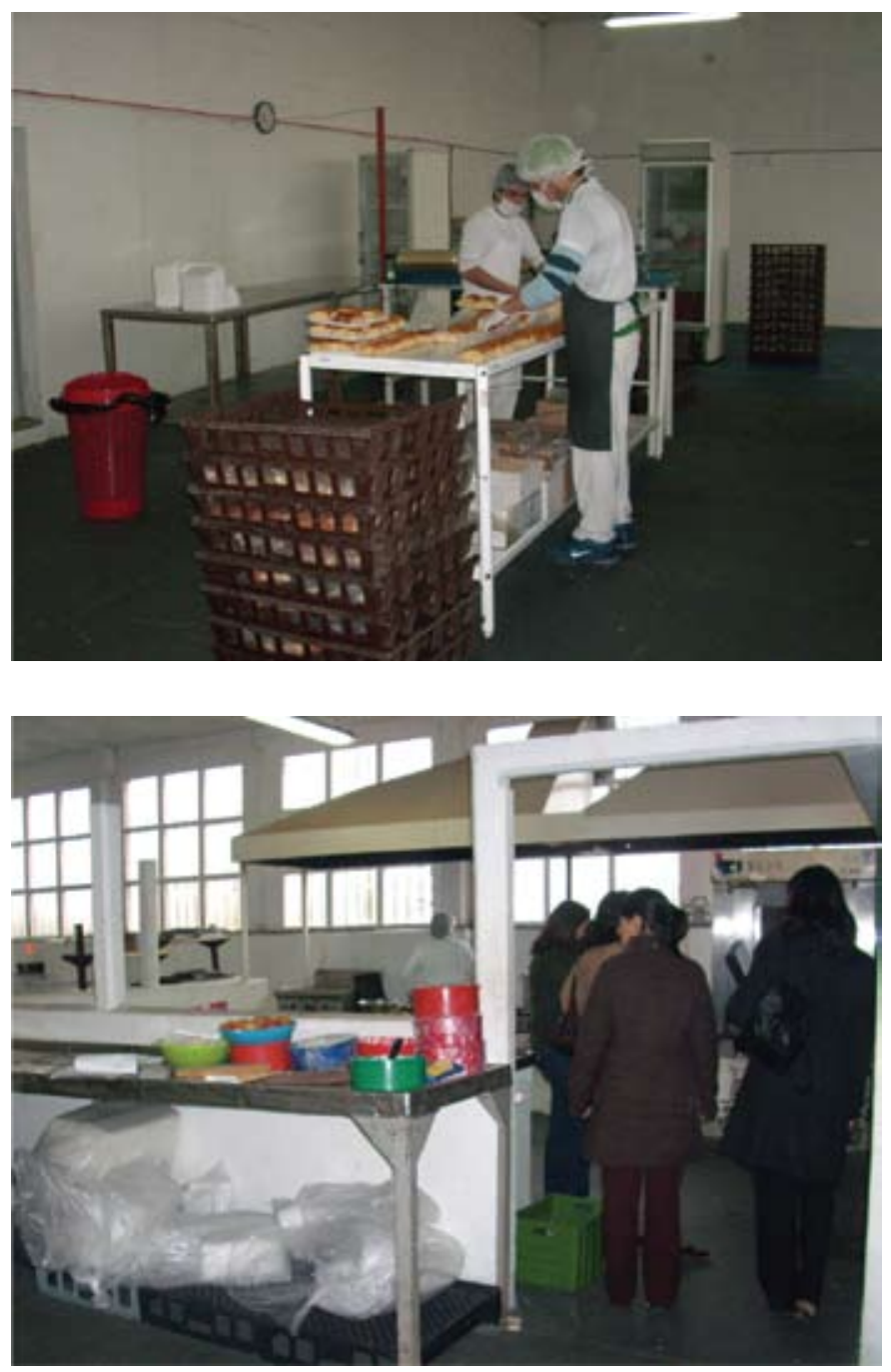

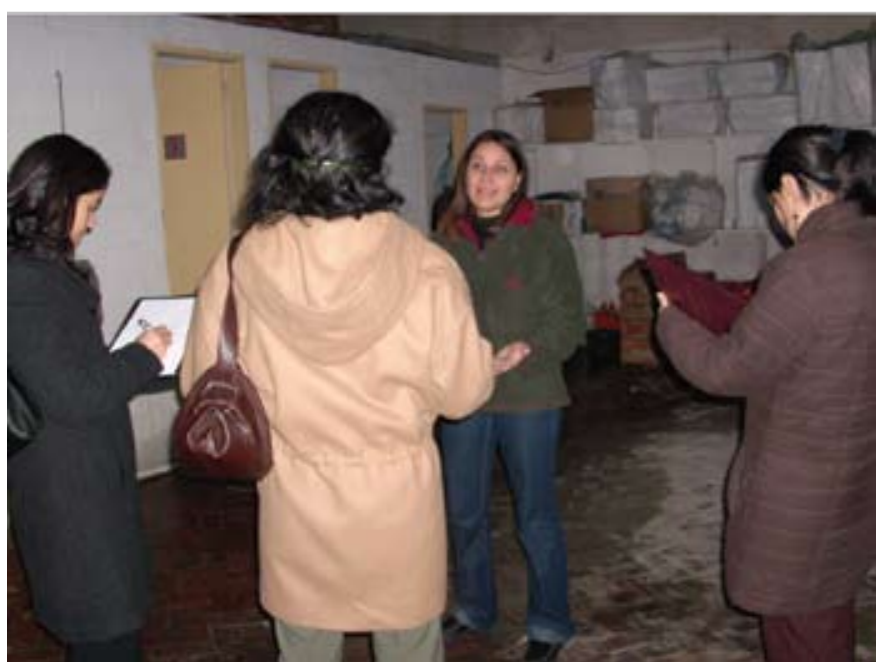

Figura 6 - Asistencia Técnica en industria del sector Alimenticio.

dos, relacionados al área Textil y a la temática de Plan de Negocios.

El trabajo desarrollado en el PTIC, puso de manifiesto la importancia
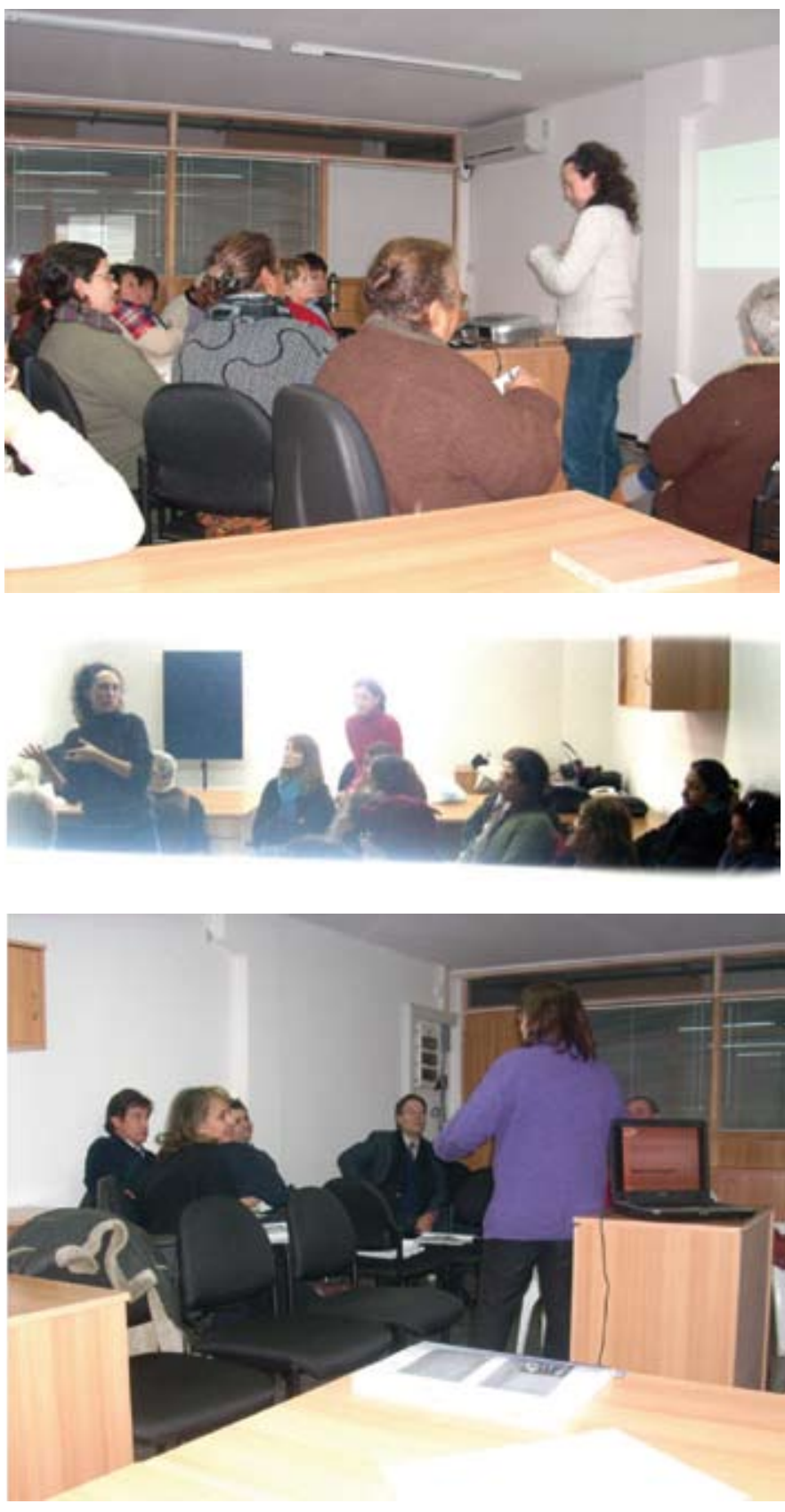

Figura 7 - Talleres brindados en el Parque. 
de tres puntos claves para lograr una buena interacción entre el sector productivo y el sector del conocimiento. En primer lugar, el acercamiento de los actores capaces de transmitir conocimientos que mejoran el desempeño de las empresas. En segundo lugar, la disponibilidad de información que sirva a las empresas, que muchas veces no se enteran de oportunidades importantes. Y por último, la motivación de las empresas para que den el paso hacia la mejora continua.

\section{Conclusiones}

$\mathrm{E}$ contacto directo y diario con las empresas, que proporciona a oficina localizada en el lugar, ha fluidizado el diálogo de los empresarios con técnicos y profesionales, así como con instituciones dedicadas a apoyar emprendimientos. Esta presencia del LATU, también ha permitido hacer llegar de una forma más sistemática las noticias, los eventos, los llamados y la información sobre los mecanismos existentes de apoyo a las empresas (como subvenciones, créditos y otros), gubernamentales o privados. Además, la metodología permitió que las empresas tuvieran la opinión y el apoyo de recursos humanos calificados para abordar sus problemáticas.

El resultado más importante ha sido poner a disposición de las empresas herramientas para desarrollar y aumentar la competitividad de las mismas, en una forma genuina y duradera, ya que fortalecen a las empresas y las capacidades de las personas. No como otros subsidios, beneficios o favores, que si bien son necesarios, cuando ya no están, las empresas corren el riesgo de no poder funcionar en una forma sustentable.

\section{Referencias}

- Casulo, M.; Pippolo, D.; Zwiebach, D. Necesidad de conocimiento en las Mypes. Montevideo : ORT, 2007.

- LATU; PTI. Convenio marco de objetivos de la oficina de LATU en PTI

- De Moura Castro, C. 1997. Proyecto joven: nuevas soluciones y algunas sorpresas. En: Boletín técnico interamericano de formación profesional. 139-140

- Jacinto, C. 2000. Jóvenes vulnerables y políticas públicas de formación y empleo. En: Revista de Estudios de Juventud. (1) :103-121

- Mitnik, F. 1997. Proyecto joven : la capacitación laboral como herramienta de equidad social. En: Boletín técnico interamericano de formación profesional. 139-140

Nota: V Simposio Internacional de Análisis Organizacional El campo organizacional y las nuevas fronteras de lo público y lo privado Eje temático: Gobierno, toma de decisiones, liderazgo participación. 